\title{
ANALISIS PEMUNGUTAN DAN PENCATATAN PAJAK BUMI DAN BANGUNAN PEDESAAN DAN PERKOTAAN (PBB - P2) PADA PEMERINTAH KABUPATEN MINAHASA TENGGARA
}

\author{
Lisa Tivani Langi ${ }^{1}$, David P.E. Saerang ${ }^{2}$, Jessy D.L.Warongan ${ }^{3}$ \\ 1,2,3 Jurusan Akuntansi, Fakultas Ekonomi dan Bisnis, Universitas Sam Ratulangi, J1. Kampus Bahu, Manado, \\ 95115, Indonesia \\ E-mail : Lisativanilangi@gmail.com
}

\begin{abstract}
At first PBB-P2 was levied by the central government. The transfer of UN-P2 in Southeast Minahasa district begins on January 1, 2014 and is expected to increase the Local Revenue $(P A D)$ and at the same time improve the structure of Regional Revenue and Expenditure Budget (APBD), improve public services, accountability and transparency in the management of PBB-P2. The purpose of this study was to analyze how the collection and recording of PBB-P2 at the Government of South Minahasa District. The purpose of this research is to know and analyze the collection and recording of PBB-P2 in South Minahasa. The type of research used is descriptive qualitative research. The result of the research shows that the PBB-P2 collection in Southeast Minahasa Regency still has obstacles, namely Taxpayer Notification Name (SPPT) which isn't in accordance with the name of tax object, the existence of double SPPT, the SPPT but the location of the tax object is unknown, the lack of awareness in making the payment of $P B B-P 2$ by taxpayers domiciled outside the region but has a tax object in the region. Recording of $P B B-P 2$ revenue is still the difference between budget realization of PBB-P2. It is recommended that the Regional Finance Board of Southeast Minahasa hold socialization to local governments and local communities regarding the implementation of $P B B-P 2$ collections, so that taxpayers have a concern in the case of PBB-P2 payments on time and active in reporting the object/subject of tax when there are problems encountered.
\end{abstract}

Keywords : Collection, accounting records, PBB-P2

\section{PENDAHULUAN}

Pajak adalah kewajiban yang dibayarkan oleh masyarakat baik secara perorangan maupun badan dari penghasilan masyarakat kepada pemerintah yang diperuntukkan melakukan kegiatan bermanfaat bagi negara. Pembagian pajak berdasarkan wewenang pemungut ada 2, yaitu pajak pusat dan pajak daerah. Pajak pusat kewenangannya berada pada pemerintah wilayah pusat dan pajak daerah wewenang pemungutan pada pemerintah wilayah daerah. Berbagai jenis pajak dan retribusi antara lain PPh, PPN, PPnBM, PBB.

Pemerintah Kabupaten Minahasa Tenggara menjalankan kewenangan atas pengalihan PBB-P2 pada 1 Januari tahun 2014. Ini menjadi peluang dan tantangan bagi pemerintah dalam meningkatkan PAD. Dalam pemungutan dan pencatatan PBB-P2 perlu untuk diketahui bagaimana proses pemungutan dan pencatatan yang dilakukan oleh pengelolah PBB-P2 di Badan Keuangan Daerah Minahasa Tenggara.

Berdasarkan latar belakang diatas, maka saya mengangkat judul "Analisis Pemungutan dan Pencatatan Pajak Bumi dan Bangunan Pedesaan dan Perkotaan (PBB-P2) pada Pemerintah Kabupaten Minahasa Tenggara" 


\section{TINJAUAN PUSTAKA}

\subsection{Akuntansi}

Akuntansi merupakan suatu alat komunikasi yang bisa memberikan informasi mengenai posisi keuangan dan perubahan posisi keuangan dalam hal jumlah assets, liability dan equity dari suatu usaha.

\subsection{Pajak}

Pajak adalah kewajiban yang bisa dipaksakan dengan tujuan untuk membiayai pengeluaran pemerintah.

\subsection{Akuntansi Pajak}

Suatu proses pencatatan transaksi keuangan yang berkaitan dengan kewajiban perpajakan.

\subsection{Pajak Bumi dan Bangunan (PBB)}

PBB adalah iuran oleh orang atau badan yang memiliki hak menguasai dan memperoleh manfaat dari bumi dan bangunan.

\subsubsection{Dasar Hukum Pajak Bumi dan Bangunan}

Dasar hukum pemungutan PBB yaitu sebagai berikut:

1. Undang-undang Nomor 12 Tahun1994 tentang PBB;

2. Peraturan pemerintah Nomor 25 Tahun 2002 mengenai penetapan besarnya NJKP perhitungan PBB;

3. Keputusan Menteri keuangan No. 1002/KMK.04/1985 sebagaimana diubah dengan keputusan menteri keuangan No. 617/KMK.01/1989 tentang pendataan objek dan subjek PBB;

4. Keputusan Menteri Keuangan No. 1007/KMK.04/1985 tentang Pelimpahan Wewenang Penagihan PBB kepada Gubernur Daerah atau Bupati/Walikota;

5. Undang-undang Nomor 12 Tahun 1994;

6. Aturan pelaksanaan lainnya.

\subsubsection{Asas Pajak Bumi dan Bangunan}

Asas Pajak Bumi dan Bangunan menurut Samudra (2015:263) yaitu sebagai berikut.

1. Sederhana

2. Adil

3. Kepastian dan Hukum

4. Gotoeng Royong

\subsubsection{Objek Pajak}

Bumi dan bangunan.

\subsubsection{Subyek Pajak Bumi dan Bangunan}

Orang pribadi atau badan yang mempunyai hak atas bumi, dan memperoleh manfaat atas bumi serta bangunan.

\subsubsection{Dasar Pengenaan PBB dan Tarif Perhitungan PBB}

1. NJOP sebagai dasar pengenaan PBB.

2. NJOPTKP adalah batas NJOP bumi dan bangunan yang tidak kena pajak.

3. NJKP merupakan dasar perhitungan PBB.

4. Tarif PBB $0.5 \%$

\subsubsection{Dasar Penagihan PBB}

1. SPPT

2. SKP

\subsubsection{Surat Tagihan Pajak}

\section{a. Dasar penerbitan STP}

\subsubsection{Surat Pemberitahuan Objek Pajak (SPOP)}

Pendataan PBB Pedesaan dan perkotaan dilakukan dengan menggunakan SPOP. SPOP harus diisi dengan benar serta ditanda tangani dan disampaikan kepada 
pemerintah setempat yang wilayah kerja meliputi letak obyek pajak, selambatlambatnya 30 hari kerja setelah tanggal diterimanya SPOP oleh subyek pajak.

\subsubsection{Tahun Pajak dan Tempat yang Penentuan Pajak Terutang} Jangka waktu 1 (satu) tahun takwin.

\subsubsection{Penetapan Nilai Jual Objek Pajak} Jenis Objek Pajak :

Obyek pajak menjadi 2 klasifikasi, yaitu objek pajak umum dan objek pajak khusus.

\subsubsection{Pendekatan Penilaian}

Penetapan NJOP dipakai 3 metode yaitu :

1. Pendekatan Data Dasar (Market Data Approach)

2. Pendekatan Biaya (Cost Approach)

3. Pendekatan Pendapatan (Income Approach)

\subsubsection{Cara Penilaian}

1. Penilaian Tanah

2. Penilaian Bangunan Dalam menilai bangunan untuk keperluan PBB dilakukan dengan 2 (dua), yaitu Penilaian Massal dan Penilaian Individual.

\subsection{Faktor yang Mempengaruhi Nilai Tanah dan Bangunan}

1. Faktor ekonomi,

2. Faktor sosial

3. Faktor pemerintah

4. Faktor fisik

\subsection{Pendapatan Asli Daerah}

Pendapatan Asli Daerah adalah semua penerimaan yang diperoleh daerah dari sumbersumber dalam wilayahnya sendiri yang dipungut berdasarkan peraturan daerah sesuai dengan peraturan perundang-undangan yang berlaku.

\section{METODE PENELITIAN}

\subsection{Jenis Penelitian}

Jenis penelitian yaitu kualitatif. Saya secara langsung mendatangi obyek penelitian di Badan Keuangan Daerah Kabupaten Minahasa Tenggara untuk memperoleh data-data dan informasi yang dibutuhkan dalam menganalisis pemungutan dan pencatatan PBB-P2.

\subsection{Tempat dan Waktu Penelitian}

Penelitian ini dilakukan pada BKD Minahasa Tenggara sebagai pihak pengelolah pemungutan PBB-P2 Kabupaten Minahasa Tenggara.Proses penelitian ini dimulai pada September 2017 - Februari 2018.

\subsection{Prosedur Penelitian}

1) Survei

2) Identifikasi Objek

3) Pengumpulan Data

4) Analisis Data

5) Kesimpulan dan Saran

\subsection{Metode Pengumpulan Data}

1. Jenis Data

Data yang dipakai dalam penelitian ini yaitu data kualitatif didapat dari hasil diwawancarai terhadap pengelolah PBB-P2.

\section{Sumber Data}
1. Data Primer 
Menurut Fathoni (2011: 30) yakni data yang diambil langsung dari sebuah perusahaan. Yang diwawancara pihak terkait di Dinas Pendapatan Daerah Kabupaten Minahasa Tenggara, tentang pemungutan dan pencatatan yang dilakukan.

2. Data Sekunder

Menurut fathoni (2011: 38) merupakan data yang diperoleh dari sumbernya serta tulisan-tulisan yang menyangkut penelitian.

\section{Teknik Pengumpulan Data}

Teknik yang saya gunakan dalam pengumpulan data dengan menggunakan cara Mewawancarai dan dokumentasi.

\subsection{Metode Analisis}

Metode yang dipakai dalam penelitian adalah deskriptif yaitu metode yang buat dengan cara mengumpulkan, menyajikan, serta menganalisis data kemudian ditarik suatu kesimpulan mengenai pemungutan dan pencatatan PBB-P2.

\section{HASIL ANALISIS DAN PEMBAHASAN}

4.2.1 Prosedur Pemungutan Pajak Bumi dan Bangunan Pedesaan dan Perkotaan (PBB-P2) pada Pemerintah Kabupaten Minahasa Tenggara Peraturan Daerah Nomor 5 Tahun 2013

Pada Pemerintahan di Kabupaten Minahasa Tenggara dalam melaksanakan pemungutan PBB-P2 telah dipersiapkan :

1. Peraturan Daerah

Dasar untuk pelaksanaan pemungutan PBB-P2 pada Kabupaten Minahasa Tenggara.

2. Menyediakan Sumber Daya Manusia (SDM) serta sarana dan prasarana.

Dalam hal untuk meningkatkan kinerja dari panita pelaksana pemungutan PBB-P2

3. Menggunakan aplikasi Sistem Informasi dan Manajemen Objek Pajak (SISMIOP) sebagai aplikasi dalam proses pengelolaan administrasi PBB Pedesaan dan Perkotaan yang meliputi kegiatan sbb :
a. Pendaftaran;
b. Pendataan;
c. Penilaian;
d. Penetapan ; dan
e. Penerimaan.

Pemerintah setempat bisa mengembangkan Sistem Informasi dan Manajemen Objek Pajak sesuai keperluan dan perkembangan technology.

\subsubsection{Prosedur Pelaksanaan Pemungutan PBB-P2 Pada Pemerintah Kabupaten Minahasa Tenggara}

Saya melakukan penelitian tentang pelaksanaan pemungutan PBB-P2 di BKD Minahasa Tenggara danm mewawancarai beberapa pegawai yang mengelola PBB-P2. Saya menanyakan tentang tekhnis pelaksanaan prosedur pemungutan PBB-P2. Pertanyaan penulis yang diajukan mengarah pada Peraturan Daerah Nomor 18 Tahun 2014 sebagai acuan dan dasar hukum pelaksanaannya pada Pemerintah Kabupaten Minahasa Tenggara.

\subsubsection{Pencatatan PBB-P2 di BKD Minahasa Tenggara}

Badan Keuangan Daerah (BKD) Minahasa Tenggara yaitu Badan yang menghimpun dana salah satunya mengenai PBB-P2 di Minahasa Tenggara. Dari beberapa proses yang ada memasuki pada tahap akhir setiap transaksi-transaksi ataupun pembayaran dan penyetoran dana dari wajib pajak baik melalui tempat pembayaran PBB-P2 yaitu kepada pemerintah setempat maupun Tempat Pembayaran Elektorik (TPE) akan dilaporkan ke Bendahara penerimaan. Bendahara penerimaan melakukan rekapitulasi penerimaan PBB-P2, seteleh itu dilakukannya rekonsiliasi antara bendahara penerimaan dan rekening koran. Kemudian realisasi penerimaan $\mathrm{PBB}-\mathrm{P} 2$. 
Jurnal untuk pendapatan PBB-P2 pada BKD Kabupaten Minahasa Tenggara adalah sebagai berikut:

1. Saat menerima pembayaran atas PBB-P2 oleh wajib pajak ke bendahara Penerimaan.

Kas di bendahara penerimaan

Piutang PBB-P2

$859,000,000$

2. Saat wajib pajak melakukan penyetoran langsung ke bank
Kas RKUD
$264,000,000$

2. Saat wajib pajak melakukan penyetoran langsung ke bank
Kas RKUD
$264,000,000$

2. Saat wajib pajak melakukan penyetoran langsung ke bank
Kas RKUD
$264,000,000$

Pendapatan PBB-P2

$859,000,000$

3. Pada saat reconsiliasi bendahara penerimaan dan penyetoran $\mathrm{PBb}-\mathrm{P} 2$ lewat bank oleh wajib pajak

Kas RKUD

Pendapatan PBB-P2

$1,123,908,842$

$264,000,000$

\subsection{Pembahasan}

\subsubsection{Pemungutan PBB-P2 di Minahasa Tenggara}

Hasil penelitian diatas, pelaksanaan pemungutan oleh pengelolah di BKD Kabupaten Minahasa Tenggara secara umum berjalan dengan baik dan telah sesuai dengan peraturan yang berlaku. Tetapi adapun yang menjadi hambatan yang dihadapi oleh pengelolah PBB-P2 mengenai pelaksanaan pemungutan PBB-P2 yaitu masih terjadi kesalahan dalam Nama SPPT yang tidak sesuai dengan nama objek pajak, adanya SPPT ganda, SPPTnya ada tapi letak objek pajak tidak diketahui, ketika ada wajib pajak meninggal dunia atau ketika objek pajak telah dialihkan, kurangnya perhatian dari masyarakat dan pemerintah dalam hal melaporkan kepada pihak yang berwenang untuk diperbaharui data dari wajib pajak tersebut. Hal ini menjadi kendala bagi pengelolaan PBB-P2.

\subsubsection{Pencatatan PBB-P2 di Minahasa Tenggara}

Adapun di dapati saat pembayaran PBB-P2 oleh wajib pajak dari berbagai daerah terdapat selisih realisasi anggaran PBB-P2 di Kabupaten Minahasa Tenggara. Berikut adalah daftar tabel realisasi PBB-P2 Tahun 2016 di Kabupaten Minahasa Tenggara. Tabel 4.4

\section{KESIMPULAN DAN SARAN}

\subsection{Kesimpulan}

Kesimpulan yang dapat ditarik dari penelitan ini yaitu:

1. Pemungutan Pajak Bumi Bangunan Pedesaan dan Perkotaan (PBB-P2) di Minahasa Tenggara telah sesuai dengan ketentuan umum yang berlaku. Tetapi masih terdapat hambatan oleh pengelolah PBB-P2 mengenai pelaksanaan pemungutan PBB-P2 yaitu masih terjadi kesalahan dalam nama SPPT yang tidak sesuai dengan nama WP, adanya SPPT ganda, SPPTnya ada tapi letak objek pajak tidak diketahui, ketika ada wajib pajak meninggal dunia atau ketika objek pajak telah dialihkan, kurangnya perhatian dari masyarakat dan pemerintah dalam hal melaporkan kepada pihak yang berwenang untuk diperbaharui data dari wajib pajak tersebut.

2. Dalam proses pencatatan penerimaan PBB-P2 di Minahasa Tenggara telah seuai dengan ketentuan umum yang berlaku tapi masih terdapat selisih realisasi anggaran PBB-P2 di Badan Keuangan Daerah Minahasa Tenggara. Lewat tabel 4.3 telah dijelaskan bahwa masih ada selisih atau sisa pembayaran dari wajib pajak untuk pembayaran PBB-P2 di tahun 2016 masih ada $3.31 \%$ wajib pajak yang belum membayar pajak.

\subsection{Saran}

Berdasarkan dari penelitian ini penulis menyarankan kepada Badan Keuangan Daerah (BKD) Minahasa Tenggara untuk mengadakan sosialisasi kepada pemerintah daerah dan masyarakat setempat menyangkut pelaksanaan pemungutan PBB-P2, serta manfaat dari pembayaran pajak PBB-P2, sehingga wajib pajak memiliki kepedulian dalam hal pembayaran 
PBB-P2 tepat waktu dan aktif dalam melaporkan objek/subjek pajak ketika ada masalah yang dihadapi. Dalam hal ini dapat menunjang kinerja dari pengelolah PBB-P2 dalam tahap perbaikan data dari objek/subjek pajak serta dapat meningkatkan pendapatan daerah dalam hal menunjang setiap program-program yang telah di buat oleh Pemerintah Kabupaten Minahasa Tenggara.

\section{DAFTAR PUSTAKA}

Adriani (2011). Penagihan Pajak: Pajak Pusat dan Pajak Daerah. Bogor: Ghalia Indonesia Abdurrahmat Fathoni. 2011. Metodologi Penelitian dan Teknik Penyusunan Skripsi. Jakarta : PT.Rineka Cipta

Anton, Carmen, Cristinel Constantin. 2013. The Accounting-Taxation Relantionship In The Opinion Of The Financial-Accounting Services Providers. Transilvania University of Brasov, Romania. Journal of Applied Economic Science. Vol. VIII Issue 2(24) ISSN:1843-6110.

Attawodi, Ojochogwu Winnie \& Ojeka, Stephen Aanu. 2012. Factors That Affect Tax Compliance among Small and Medium Enterprises (SMEs) in North Central Nigeria. International Journal Of Business and Management Toronto. Vol. VII Issue 12 ISSN: 1833-3850.

Ghasemi Maziyar, Shafeiepour Vahid, Aslani Mohammad, Barvayeh Elham. 2011. The Impact Of Information Technology (IT) On Modern Accounting Systems. Islamic Azad University, Tosyerkan Iran. Procedia Social and Behavioral Sciences. Vol 28 ISSN: 1877-0428.

Giri, Efraim F. 2012. Akuntansi Keuangan Menengah 1. UPP STIM YKPN. Yogyakarta.

Hery, 2014. Akuntansi Perpajakan. Grasindo, Jakarta.

Harahap. 2011. Teori Akuntansi. Edisi Terbaru 2011. Jakarta

Khasanah, Septiyani, Nur. 2014. Pengaruh Pengetahuan Perpajakan, Modernisasi Sistem Administrasi Perpajakan, dan Kesadaran Wajib Pajak Terhadap Kepatuhan Wajib Pajak pada Kantor Wilayah Direktorat Jenderal Pajak Daerah Istimewa Yogyakarta Tahun 2013. Universitas Negeri Yogyakarta.

Mardiasmo. 2016. Perpajakan. Edisi 2016

Peraturan Menteri keuangan Nomor 23/PMK.03/2014

Peraturan Bupati Minahasa tenggara Nomor 18 Tahun 2014 tentang sistem dan prosedur pemungutan pajak bumi dan bangunan pedesaan dan perkotaan.

Plimmer, 2015. The basis and administration of the property tax: what can be learned from internasional practice

Samryn. 2011. Pengantar Akuntansi. Salemba Empat, Jakarta.

Samudra, A. A. 2015. Pepajakan di Indonesia. Keuangan, Pajak dan Retribusi Daerah. Jakarta PT Raja Grafindo Persada

Suandy, Erly. "Perencanaan pajak." Jakarta: Salemba Empat (2011).

Sugiyono, Prof. "Dr. 2014." Metode Penelitian Kuantitatif, Kualitatif dan R\&D. Cetakan Ke15. Alfabeta: Bandung.

Sumarsan, Thomas. 2013. Perpajakan Indonesia: Pedoman Perpajakan yang Lengkap Berdasarkan Undang-Undang Terbaru. Indeks, Jakarta.

Supramono \& Theresia. 2015.Perpajakan Indonesia: Mekanisme dan Perhitungan. Andy, Yogyakarta.

Supriyanto, Eddy. 2011. Akuntansi Perpajakan. Edisi Pertama. Graha Ilmu, Yogyakarta.

Waluyo, 2013. Perpajakan Indonesia. Jakarta. Penerbit: Salemba Empat. 